\title{
Correction to: Delivering fracture prevention services to rural US veterans through telemedicine: a process evaluation
}

\author{
Karla L. Miller ${ }^{1,2,3}$ - Melissa J. Steffen ${ }^{1,4,5} \cdot$ Kimberly D. McCoy ${ }^{4,5} \cdot$ Grant Cannon $^{2}$ - Aaron T. Seaman ${ }^{4,6}$. \\ Zachary L. Anderson ${ }^{1,7}$. Shardool Patel ${ }^{1,7,8}$. Janiel Green ${ }^{1,9}$. Shylo Wardyn ${ }^{4}$. Samantha L. Solimeo ${ }^{4,5,6}$
}

Published online: 7 April 2021

(C) International Osteoporosis Foundation and National Osteoporosis Foundation 2021

\section{Correction to: Archives of Osteoporosis (2021) 16:27} https://doi.org/10.1007/s11657-021-00882-0

The article Delivering fracture prevention services to rural US veterans through telemedicine: a process evaluatio, written by Karla L. Miller, Melissa J. Steffen, Kimberly D. McCoy, Grant Cannon, Aaron T. Seaman, Zachary L. Anderson, Shardool Patel, Janiel Green, Shylo Wardyn, Samantha L. Solimeowas originally published online on 10 February 2021 with Open Access under a original Creative Commons Attribution (CC BY) licence 4.0. After publication in volume 16, issue 1, article number: 27 (2021) the author(s) decided to cancel the Open Access. Therefore, the copyright of the article

The online version of the original article can be found at https://doi.org/ $10.1007 /$ s $11657-021-00882-0$

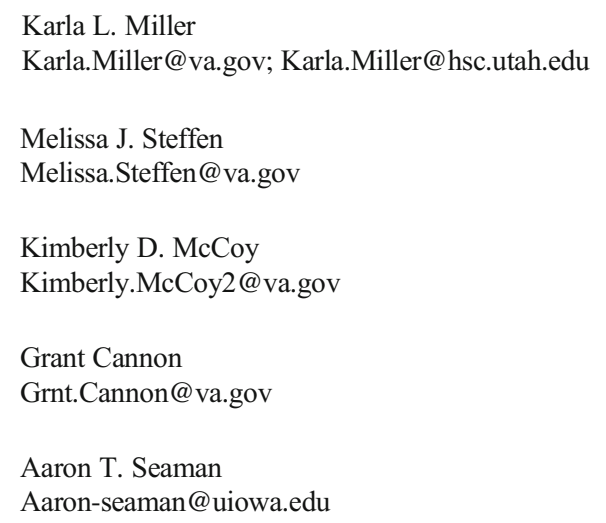

has been changed on 02 March 2021 to (C) This is a U.S. government work and not under copyright protection in the U.S.; foreign copyright protection may apply 2021 with all rights reserved.

Publisher's note Springer Nature remains neutral with regard to jurisdictional claims in published maps and institutional affiliations.

\author{
Zachary L. Anderson \\ Zachary.Anderson3@va.gov \\ Shardool Patel \\ Shardool.patel@va.gov \\ Janiel Green \\ Janiel.Green@va.gov \\ Shylo Wardyn \\ shylo.wardyn@va.gov \\ Samantha L. Solimeo \\ Samantha-solimeo@uiowa.edu
}

Extended author information available on the last page of the article 


\section{Affiliations}

Karla L. Miller ${ }^{1,2,3} \cdot$ Melissa J. Steffen ${ }^{1,4,5} \cdot$ Kimberly D. McCoy $^{4,5} \cdot$ Grant Cannon $^{2}$ - Aaron T. Seaman ${ }^{4,6}$. Zachary L. Anderson ${ }^{1,7}$. Shardool Patel ${ }^{1,7,8}$ • Janiel Green ${ }^{1,9} \cdot$ Shylo Wardyn ${ }^{4}$. Samantha L. Solimeo ${ }^{4,5,6}$

1 VA Office of Rural Health, Veterans Rural Health Resource CenterSalt Lake City (VRHRC-SLC), Salt Lake City, UT, USA

2 Department of Internal Medicine, Rheumatology Section, Veterans Affairs Salt Lake City Health Care System, Salt Lake City, UT, USA

3 Division of Rheumatology, University of Utah School of Medicine, Salt Lake City, UT, USA

4 VA Office of Rural Health, Veterans Rural Health Resource CenterIowa City (VRHRC-IC), Salt Lake City, UT, USA

5 Comprehensive Access \& Delivery Research and Evaluation (CADRE), Primary Care Analytics Team Iowa City (PCAT-IC),
Department of Veterans Affairs, CADRE, Iowa City VA HCS, Research 152, 601 Highway 6 West, Iowa City, IA 52246, USA

6 Division of Genera 1 Internal Medicine, Department of Internal Medicine, University of Iowa Carver College of Medicine, 200 Hawkins Drive, Iowa City, IA 52242, USA

7 Department of Anesthesiology, Veterans Affairs Salt Lake City Health Care System, Salt Lake City, UT, USA

8 Division of Epidemiology, Department of Internal Medicine, University of Utah School of Medicine, Salt Lake City, UT, USA

9 Veterans Affairs Salt Lake City Health Care System, Salt Lake City, UT, USA 